\title{
Reducing Spray Drift and Increasing Spreading Effect of the Thifluzamide Through the Use of Adjuvants and Nozzles
}

Gong CW' ${ }^{1}$ Ma $Y^{1}$, Liu YH ${ }^{2}$, Wang XG ${ }^{1 *}$, Zhan XX' Yang $R^{1}$, Ruan $Y^{1}{ }^{1}, L_{i} B^{3}$, Shen $L T^{1}$ and Zhan $X^{4}$ ${ }^{1}$ Biorational Pesticide Research Lab, Sichuan Agricultural University, China

${ }^{2}$ College of Plant Protection, Southwest University, China ${ }^{3}$ Chengdu Green Gold High-tech Co., Ltd., China

${ }^{4}$ Chongqing Jian'an Instrument Co., Ltd., China

*Correspondling author: Xuegui Wang, Biorational Pesticide Research Lab, Sichuan Agricultural University, Chengdu 611130, China

Received: February 10, 2021; Accepted: March 11, 2021; Published: March 18, 2021

\begin{abstract}
Spray drift, as a practical issue during Unmanned Aerial Vehicle (UAV) spraying, has a negative impact on the environment, and the use of air-induction nozzles or anti-drift adjuvants are the most common recommendations for reducing drift. To screen the adjuvants for favourable atomization performance and anti-drift effect, we evaluated the spray atomization performance of different adjuvants by the droplet size measurement system. From the wind tunnel results, we commented on the relationship among the atomization performance, drift distance and drift deposition, and determined the drift percentage of different nozzles and the surface tension of liquids with different adjuvants. The results showed that the addition of adjuvants would modify the distribution span $\mathrm{S}, \Phi \mathrm{Vol}_{<150 \mu \mathrm{m}}$ and the volume medium diameter $\mathrm{D}_{50} ; \Phi \mathrm{Vol}_{<150 \mathrm{um}}$ and $\mathrm{D}_{50}$ of the Maifei treatment decreased and increased the most of all the treatments. There were negative correlations between the drift distance, $D_{50}$ and percentage of drift amount. The adjuvants Maifei and the nozzle IDK120-015 significantly decreased the drift deposition amount. And the anti-drift effect of nozzle IDK120-015 plus Maifei was significantly stronger than that of other nozzles or adjuvants. In addition, the addition of adjuvants could significantly decrease the surface tension, especially for Maifei. These results suggest that the addition of Maifei is an effective way to reduce the spray drift for all nozzle types and lessen the surface tension. These data help to provide a theoretical basis for selecting suitable nozzles and adjuvants for plant protection UAVs.
\end{abstract}

Keywords: Spray drift; Unmanned aerial vehicles; Anti-drift adjuvants; Airinduction nozzles; Anti-drift effect; Surface tension

\section{Introduction}

Pesticides are commonly sprayed using manual sprayers in China. However, in 2002, the Ministry of Agriculture of China organized different local plant protection departments to survey plant protection sprayers in the field and found that there was serious running, dropping, dropping and leaking phenomena of various manual sprayers (100 million of the social holdings), resulting in the effective utilization rate of pesticides being less than $30 \%$ [1]. Compared with traditional automatic or semi-manual plant protection equipment, plant protection Unmanned Aerial Vehicles (UAVs) have the advantages of high spraying efficiency, performance, and precision; thus, plant protection UAVs are increasingly being applied in the control of crop pests [2], especially for rice protection. Due to the canopy overlap, occurring in rice cultivation, crop spraying using automatic or semi-manual machines is inconvenient for controlling diseases, insect pests and weeds. Qin et al. [3] found that the deposition and distribution of droplets in the lower layer were higher and more uniform when crop spraying was executed by UAVs and the insecticidal efficacy and the persistence period were greater than those achieved with a hand lance operated from a stretcher-mounted sprayer. The popularization of plant protection UAVs provides a useful operating platform for preventing rapid outbreaks of pests and diseases in rice paddy fields and for upgrading technology for rice protection.

As an emerging technology, UAV spraying for crop protection can induce many practical issues; especially spray drift [2]. Due to the influence of air operation conditions and air flow, compared with ground-based plant protection aircraft, plant protection UAVs were more likely to produce spray drift [4]. Spray drift not only reduces the effective utilization rate of pesticides but also poses a serious threat to the safety of personnel, adjacent crops and the environment. With the increasing environmental awareness of the public, controlling spray drift will inevitably be the focus of spray technology research. Aerial spray drift has been studied regarding spray droplet size, nozzle configurations and so on $[5,6]$. As the core component of plant protection UAVs, the nozzle is the key factor affecting the spray drifts because a nozzle with good spray performance can improve the uniformity and amount of droplet deposition and ultimately improve the spray quality [7]. Flack et al. [8] found that when the leeward side of the air-induction nozzle JAP110-015 was tilted, it could reduce the drift by $39 \%$ compared with the drift of the conventional fan nozzle, and when the upwind side was inclined, the drift was decreased by $18.6 \%$. Therefore, choosing the right nozzle is one of the key factors in improving the reducing spray drift.

In addition to the nozzle, the properties of the liquid were also the main factors affecting the atomization performance in previous 
studies [9-11]. Butler-Ellis et al. [12] mentioned that the adjuvants were the main factors that affected the atomization performance of sprinklers. When a certain concentration of adjuvants was added, the spray angle and fan width decreased relative to those parameters measured without including adjuvants to the liquid. Ellis et al. [13] performed a detailed study on how different adjuvants affected the atomization performance of hydraulic spray nozzles, analyzed the changes in droplet size and liquid film length for different types of spray nozzles under the conditions of adding different adjuvants, and analyzed the drift index of spray droplets after atomization. Although the surface tension and viscosity of the medicinal solution during atomization were not known, there was a relationship between these properties. Additionally, some scholars studied the effects of nozzle type, size and pressure on the atomization performance [14] and the breaking mechanism of the liquid film [15-18].

The collection methods of spray drift could be divided into the ground drift collection method and the air drift collection method [19]. The ground drift collection method mainly uses petri dishes, Mylar and filter paper to collect the droplets [20]. Smith et al. [21] and Heidary et al. [11] collected ground drift data at 2, 4, 8, 16 and $27.5 \mathrm{~m}$ in the field and a wind tunnel, respectively, and found that the median volume D50, $\Phi \mathrm{Vol}<150 \mu \mathrm{m}$ and downwind distance significantly impact spray drift.

In this paper, we evaluated the spray atomization performance of different adjuvants and their effects on drift deposition by adapting plant protection UAV nozzles and screened adjuvants and nozzles with good atomization performance and good anti-drift effects to lay the foundation for reducing pesticide application via increased efficiency. The atomization performance of different types of nozzles was detected for different adjuvants during the spray process, and the relationship between atomization performance and drift deposition was analyzed by comparing the effects of different atomization properties of the nozzles and adjuvants on the drift deposition, providing a theoretical basis for selecting suitable plant protection apparatuses and adjuvants for plant protection UAVs in rice cultivation.

\section{Materials and Methods}

\section{Materials}

A $240 \mathrm{~g} / \mathrm{L}$ thifluzamide suspension (trade name: Mansui) was used as the fungicide agent and was supplied by Nissan Chemical Co., Ltd, Shanghai, China. Allura red (85\%) was supplied by Shanghai Yuanye Biotechnology Co., Ltd, Shanghai, China. SilwetL-77 and 10\% FC4430 (Fluorosurfactant) dipropylene glycol monomethyl ether solution were supplied by General Electric Co., Ltd, Boston, America and Minnesota Mining and Manufacturing Co., Ltd, Minnesota, America, respectively.

Primary Alcobol Ethoxylate, BYK-405, BYK-051N, and Isomeric alcohol ethoxylates were supplied by Shandong Yousuo Chemical Technology Co., Ltd., Linyi, China, BYK Additives (Shanghai) Co., Ltd. Shanghai, China, and Badische Anilin-und-Soda-Fabrik Co., Ltd, Ludwigshafen, Germany, respectively. Neem Crude Oil (45.97\% Oleic acid, 17.66\% Octadecanoic acid, 17.61\% Palmitic acid, 15.81\% Linoleic acid), obtained by cold pressing Neem seeds, was supplied by Chengdu Lvjin Biotechnology Co., Ltd, Chengdu, China. The tested
Table 1: The spray droplet distribution (S) of different types of adjutants.

\begin{tabular}{|l|c|c|c|}
\hline \multicolumn{1}{|c|}{ Adjutants } & $\mathbf{S} \pm \mathbf{S D}$ & $\boldsymbol{\Phi \mathbf { V o l } _ { < 1 5 0 \mu \mathrm { m } } \pm \mathbf { S D }}$ & $\mathbf{D}_{50} \pm \mathbf{S D}$ \\
\hline Blank control & $1.046 \pm 0.012^{\mathrm{dC}}$ & $48.993 \pm 0.506^{\mathrm{aA}}$ & $125.233 \pm 0.454^{\mathrm{gF}}$ \\
\hline Feiyan & $1.110 \pm 0.000^{\mathrm{CB}}$ & $50.157 \pm 1.062^{\mathrm{aA}}$ & $147.347 \pm 1.848^{\mathrm{eE}}$ \\
\hline Maifei & $1.459 \pm 0.066^{\mathrm{aA}}$ & $27.410 \pm 2.293^{\mathrm{fE}}$ & $199.637 \pm 6.861^{\mathrm{aA}}$ \\
\hline Beidatong & $1.158 \pm 0.023^{\mathrm{bB}}$ & $36.110 \pm 0.585^{\mathrm{cC}}$ & $175.067 \pm 1.559^{\mathrm{cC}}$ \\
\hline Transmicelle & $1.153 \pm 0.003^{\mathrm{bB}}$ & $44.480 \pm 0.620^{\mathrm{bB}}$ & $157.823 \pm 0.473^{\mathrm{deD}}$ \\
\hline Kongsayihao & $1.163 \pm 0.000^{\mathrm{bB}}$ & $43.433 \pm 0.598^{\mathrm{bB}}$ & $159.927 \pm 1.160^{\mathrm{dD}}$ \\
\hline Neem oil & $0.926 \pm 0.007^{\mathrm{eD}}$ & $29.500 \pm 0.345^{\mathrm{dD}}$ & $182.917 \pm 0.372^{\mathrm{bB}}$ \\
\hline$F_{6,14}$ values & 115.687 & 232.255 & 139.601 \\
\hline P values & 0 & 0 & 0 \\
\hline
\end{tabular}

Note: SD is Standard Deviation. Means within a row followed by different lowercase and uppercase letters are significantly different using the paired bootstrap test procedure ( $\mathrm{P}<0.05, \mathrm{P}<0.01$, respectively).

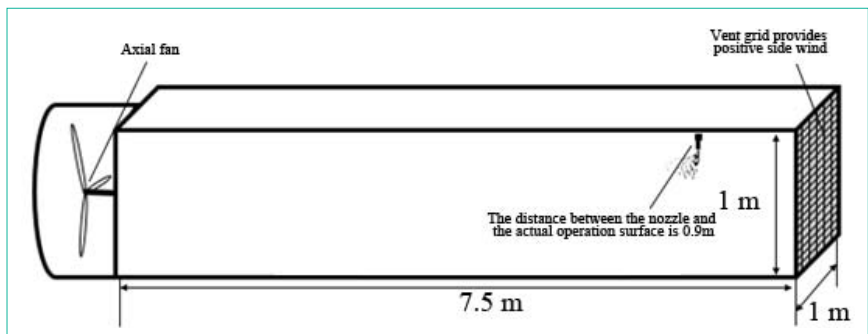

Figure 1: Schematic diagram of open wind tunnel.

nozzles were purchased from the market (Table 1).

\section{Spraying platform and spraying systems}

The atomization performance of droplets was analyzed by the droplet test platform of Anyang Quanfeng Aviation Plant Protection Technology Co., Ltd, Anyang, China. The test platform included a particle size measurement system and a spray system that could be used under different working pressures. The droplet size measurement system was composed of a laser particle sizer (DP-2, Zhuhai Europe and America Instrument Co., Ltd.) and a computer.

The spray drift test was carried out in the wind tunnel of the Key Laboratory of Aviation Plant Protection of the Ministry of Agriculture and Rural Affairs; this wind tunnel was created by Anyang Quanfeng Biotechnology Co., Ltd., and has dimensions of length $\times$ width $\times$ height $=7.5 \times 1 \times 1 \mathrm{~m}$ (Figure 1). One end of the air inlet was guided by the comb grid, and the other end had an axial-flow fan with a diameter of $0.9 \mathrm{~m}$. The fan can form a stable one-way $0 \sim 8 \mathrm{~m} / \mathrm{s}$ steeples adjustable wind speed in the working space. After the wind speed was measured by an anemometer, the wind speed value was shown on the screen of the microcomputer.

\section{Comparison of atomization performance of different adjuvants}

The nozzle (F110-015) was installed vertically above the laser beam in the test area. There was a $2 \mathrm{~m}$ distance between the nozzle and test area under the $0.3 \mathrm{MPa}$ of spray pressure. Using pure water as the blank control, $5 \mathrm{~mL}$ of each adjuvant was diluted with $1 \mathrm{~L}$ of water to create the test solution, and the distribution of droplet particles in different treatments was measured, with triplicates tested for each treatment. The distribution of droplet size was represented by tables or graphs, and the droplet size values were recorded at $10 \%, 50 \%$ and 
$90 \%$ of the total volume. $\mathrm{D}_{10}$ stands for the $10 \%$ cumulative distribution in all droplet diameters, that is, this droplet diameter range accounts for no more than $10 \%$ of the total number of droplets; similarly, $\mathrm{D}_{50}$ and $\mathrm{D}_{90}$ are $50 \%$ and $90 \%$ of the cumulative distribution of all the droplet diameters, respectively. The distribution span $\mathrm{S}$ delegates the distribution width of droplet size via the following formula: $\mathrm{S}$ $=\left(D_{90}-D_{10}\right) / D_{50}$; another index, $\Phi V o l<150 \mu \mathrm{m}$, is the percentage of droplet size less than $150 \mu \mathrm{m}$ for the total droplet volume [22].

\section{Effect of different adjuvants and nozzles on drift}

First, $5000 \mathrm{mg} / \mathrm{L}$ allura red and $6.5 \mathrm{mg} / \mathrm{L}$ Mansui were added to make mother liquors, and then $5 \mathrm{mg} / \mathrm{L}$ of the different adjuvants or equal volumes of water were added to create solution A (Maifei), solution B (neem oil), solution C (Transmicelle) and solution D (blank control). The ambient temperature of the spray test was from $28^{\circ} \mathrm{C}$ to $30^{\circ} \mathrm{C}$, and the relative humidity was $70 \sim 80 \%$. At $1 \mathrm{~m}, 2 \mathrm{~m}$ and $3 \mathrm{~m}$ from the downwind direction of the nozzle, droplet collectors were arranged in the plane perpendicular to the airflow direction, which was made of Mylar $(5 \mathrm{~cm} \times 8 \mathrm{~cm})$ and photo paper with a $0.3 \mathrm{~m}$ horizontal spacing. Before testing, the spray parameters were adjusted according to the ISO22369-2-2010 test procedures and basis.

In the wind tunnel, different nozzles (F100-015, F100-03, HCC8002, IDK120-015) were used to spray test solutions A, B, C and D at a $2 \mathrm{~m} / \mathrm{s}$ wind speed and a $0.3 \mathrm{MPa}$ pressure, and then the ground drift deposition amount and atomization performance were measured for different treatments. Each treatment was performed in triplicate. When the droplets on the Mylar and photo paper were dried, the Mylar and photo paper were placed into disposable gloves and put into black bags to store in a cool environment.

\section{Determination of atomization performance and estimated drift deposition of ground deposition droplets}

Each photo paper was scanned with a scanner (Epson, V600), and the particle size and density of drift deposited droplets were analyzed with the software DepositScan (ARS Headquarters Co., Ltd, Washington, United States) [23].

\section{Determination of ground drift deposition}

A total of $0.200 \mathrm{~g}$ of allura red was accurately weighed and dissolved in $100 \mathrm{ml}$ of demonized water and then further diluted to the standard solution with concentrations of $133.33,88.88,59.26,39.51,26.34$, and $17.56 \mathrm{mg} / \mathrm{L}$. Then, the absorbance values were detected with a microplate reader (Migu Molecular Instruments (Shanghai) Co., Ltd., CMax Plus) at 514nm; finally, the standard curve was obtained according to the concentrations responding to the absorbance values $\left(\mathrm{Y}=39.906 \mathrm{X}-2.7352, \mathrm{R}^{2}=0.9996\right)$

The allura red on the Mylar was eluted with $5 \mathrm{~mL}$ demonized water in an ultrasonic eluent, and its absorbance was measured at $514 \mathrm{~nm}$ with a microplate reader. The deposition amount of the allura red could be calculated according to the standard curve for assessing the accurate deposition of medicinal liquid on a unit area.

The deposition percentage per Mylar pv and anti-drift effect RT were detected via an industry standard, the MH_T1050-2012 aircraft spray drift field measurement method, with the following formula:

Drift deposition percentage per Mylar $p v=\left(\rho_{1} \times V_{1}\right) /\left(t \times V_{2} \times \rho_{2}\right)$ $\times 100$
Anti-drift effect RT $(\%)=$

$$
\frac{\sum(\mathrm{pvC} \times \text { drift distance })-\sum(\mathrm{pvT} \times \text { drift distance })}{\sum(\mathrm{pvC} \times \text { drift distance })} \times 100
$$

$\rho_{1}$, the concentration of allura red of the drift deposition; $\rho_{2}$, the concentration of the allura red of the test solution and control solution; $V_{1}$, the volume of deionized water dissolved on the Mylar; $V_{2}$, the nozzle flow; $t$, the spray time; pvC, the drift deposition percentage of nozzle F110-015 at different drift distances; pvT: the drift deposition percentage of the test nozzle at different drift distances.

\section{Determination of the surface tension of liquids}

The surface tension of various liquids under unbalanced conditions was detected with a ZL-2 automatic surface tension meter (Shandong Sanpu Kesen Instrument Co., Ltd.) using the ring method. The monitoring time range was from 0 to $180 \mathrm{~s}$ under the condition of $30 \pm 0.1^{\circ} \mathrm{C}$. Each test was repeated at least 3 times, and the difference in surface tension was within $1 \mathrm{mN} / \mathrm{m}$ [24]. $1 \mu \mathrm{L}$ of solution was added on a fresh rice leaf with a pipette, and the degree of contact between the droplet and the rice leaf was observed, in order to estimate the spreading ability.

\section{Data analysis}

The value of $S, \Phi \operatorname{Vol}_{<150 \mu \mathrm{m}}, \mathrm{D}_{50}$, the anti-drift effect and the surface tension of droplets deposited by different adjuvants were compared by using analysis of variance (ANOVA) followed by Duncan's test for multiple comparisons $(\mathrm{P}<0.05)$ with the SPSS version 17.0 software package (IBM) and were plotted by Sigmaplot 12.5. And the value of $\mathrm{S}, \Phi \mathrm{Vol}_{<150 \mu \mathrm{m}}, \mathrm{D}_{50}$, the drift deposition amounts and the drift amounts of droplets deposited by different adjuvants and nozzles drifted at different distances were compared by using analysis of multivariate followed by Duncan's test for multiple comparisons $(\mathrm{P}<0.05)$ with the SPSS version 17.0 software package (IBM).

\section{Results}

\section{Effect of different adjuvants on atomization}

When the F110-015 nozzle with a spray pressure of $0.3 \mathrm{MPa}$ was tested, the $S$ value considering the neem oil $(0.926)$ was significantly less than that of the blank treatment (no adjuvants); in contrast, the S values considering other adjuvants were significantly increased, with the maximum $S$ value of the treatment due to the addition of Maifei (1.459) (Table 1).

Compared with the blank control treatment, for the Feiyan treatment, the value of $\Phi \mathrm{Vol}_{<150 \mu \mathrm{m}}$ was higher, even though there was no significant difference between the two treatments. In contrast, the values of $\Phi \mathrm{Vol}_{<150 \mathrm{~mm}}$ were significantly lower in the other adjuvant treatments, with the largest reductions of $29.5 \%$ and $27.4 \%$ for neem oil and Maifei, respectively (Table 2).

Compared with the blank control $\mathrm{D}_{50}$ results, $\mathrm{D}_{50}$ was significantly promoted in the treatments with any adjuvants; the $\mathrm{D}_{50}$ results of the neem oil and Maifei increased to $182.9 \mu \mathrm{m}$ and $199.6 \mu \mathrm{m}$, respectively (Table 3).

\section{Drift deposition of different adjuvants and nozzles at different distances}

The deposited droplet particles of different adjuvants and nozzles at different distances were analyzed by scanning the photo paper (Figure 2), and the results are shown in Tables 4 . The results 
Table 2: Multiple comparison of $D_{50}$ of deposited droplets.

\begin{tabular}{|c|c|c|c|c|c|}
\hline Adjutants & Mean of $D_{50}(\mu \mathrm{m}) \pm S D$ & Nozzles & Mean of $D_{50}(\mu \mathrm{m}) \pm S D$ & Drift distance & Mean of $D_{50}(\mu \mathrm{m}) \pm S D$ \\
\hline Transmicelle & $567.5 \pm 613.5^{\mathrm{aA}}$ & F110-015 & $446.7 \pm 220.8^{\mathrm{bB}}$ & $1 \mathrm{~m}$ & $808.0 \pm 577.2^{\mathrm{aA}}$ \\
\hline Maifei & $438.3 \pm 280.1^{\mathrm{bA}}$ & IDK120-015 & $313.1 \pm 126.1^{\mathrm{CB}}$ & $2 m$ & $438.7 \pm 246.0^{\mathrm{bB}}$ \\
\hline \multirow[t]{2}{*}{ Neem oil } & $471.4 \pm 225.2^{\mathrm{bA}}$ & F110-03 & $405.5 \pm 216.8^{\mathrm{bcB}}$ & $3 m$ & $238.2 \pm 74.9^{c c}$ \\
\hline & & $\mathrm{HCC} 80-02$ & $847.5 \pm 722.5^{\mathrm{aA}}$ & & \\
\hline
\end{tabular}

Note: SD is standard deviation. Means within a row followed by different lowercase and uppercase letters are significantly different using the paired bootstrap test procedure ( $\mathrm{P}<0.05, \mathrm{P}<0.01$, respectively).

Table 3: Multiple comparison of span distribution (S) of deposited droplets.

\begin{tabular}{|l|c|c|c|c|}
\hline \multicolumn{1}{|c|}{ Adjutants } & Mean of S \pm SD & Nozzles & Mean of S \pm SD & Drift distance \\
\hline Transmicelle & $1.068 \pm 0.369^{\mathrm{aA}}$ & F110-015 & $1.099 \pm 0.245^{\mathrm{abA}}$ & $1 \mathrm{~m}$ \\
\hline Maifei & $0.975 \pm 0.197^{\mathrm{aA}}$ & IDK120-015 & $0.728 \pm 0.225^{\mathrm{cB}}$ & $2 \mathrm{~m}$ \\
\hline Neem oil & $1.039 \pm 0.379^{\mathrm{aA}}$ & F110-03 & $1.063 \pm 0.305^{\mathrm{bA}}$ & $3 \mathrm{~m}$ \\
\hline & & HCC80-02 & $1.213 \pm 0.318^{\mathrm{aA}}$ & $0.797 \pm 0.202^{\mathrm{cC}}$ \\
\hline
\end{tabular}

Note: SD is standard deviation. Means within a row followed by different lowercase and uppercase letters are significantly different using the paired bootstrap test procedure $(\mathrm{P}<0.05, \mathrm{P}<0.01$, respectively).

Table 4: Multiple comparison of estimated drift deposition.

\begin{tabular}{|l|c|c|c|c|c|}
\hline \multicolumn{1}{|c|}{ Adjutants } & Drift deposition \pm SD $\left(\mu \mathrm{L} / \mathbf{c m}^{2}\right)$ & Nozzles & Drift deposition \pm SD $\left(\boldsymbol{\mu L} / \mathbf{c m}^{2}\right)$ & Drift distance & Drift deposition \pm SD $\left(\boldsymbol{\mu L} / \mathbf{c m}^{2}\right)$ \\
\hline Transmicelle & $2.424 \pm 3.412^{\mathrm{aA}}$ & F110-015 & $2.063 \pm 1.432^{\mathrm{bB}}$ & $3.868 \pm 3.19^{\mathrm{aA}}$ \\
\hline Maifei & $1.870 \pm 1.748^{\mathrm{aA}}$ & IDK120-015 & $0.595 \pm 0.492^{\mathrm{cC}}$ & $2 \mathrm{~m}$ \\
\hline Neem oil & $2.126 \pm 1.588^{\mathrm{aA}}$ & F110-03 & $1.810 \pm 1.475^{\mathrm{bB}}$ & $3 \mathrm{~m}$ \\
\hline & & HCC80-02 & $4.271 \pm 3.853^{\mathrm{aA}}$ & $0.643 \pm 0.529^{\mathrm{cC}}$ \\
\hline
\end{tabular}

Note: SD is standard deviation. Means within a row followed by different lowercase and uppercase letters are significantly different using the paired bootstrap test procedure $(\mathrm{P}<0.05, \mathrm{P}<0.01$, respectively).

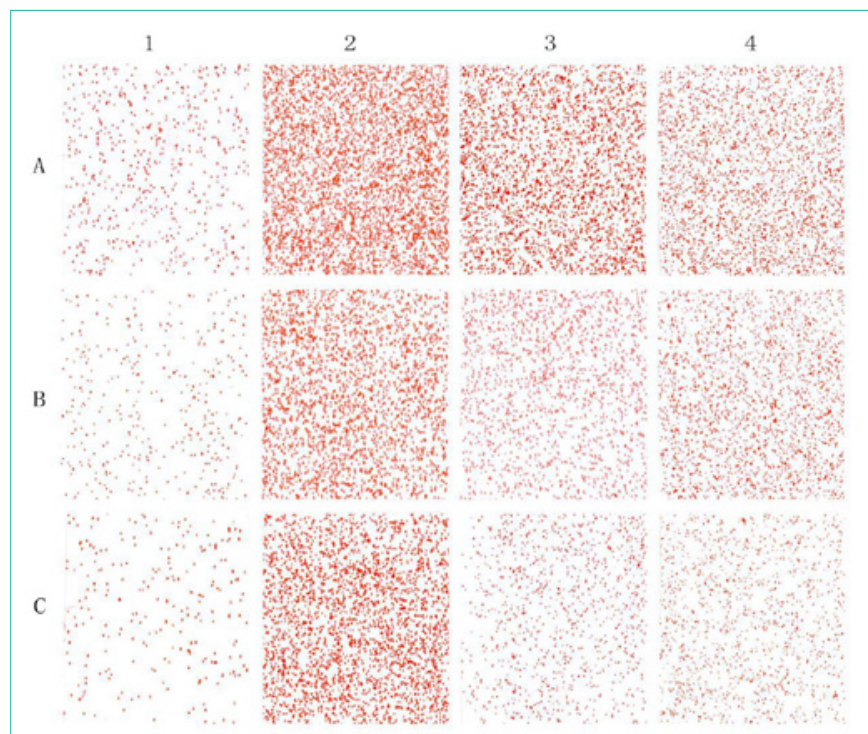

Figure 2: Performance parameters of deposition droplets with different adjuvants and nozzle models at $3 \mathrm{~m}$ of drift distances. 1: IDK120-015; 2: HCC80-02; 3: F110-015; 4: F110-03. A, B, C of swimlanes stand for the droplet drift particle size distribution used by the adjuvants Transmicelle, Neem oil, Maifei, respectively.

indicated that there was an extremely significant difference among the tested adjuvants (factor $\mathrm{A}$ ) in the droplet volume $\mathrm{D}_{50}(\mathrm{~F}=5.606$, $\mathrm{df}=2, \mathrm{P}=0.007<0.01)$; meanwhile, the droplet volumes of Maifei $(438.3 \mu \mathrm{m})$ and neem oil $(471.4 \mu \mathrm{m})$ were significantly lower than that of Transmicelle $(567.5 \mu \mathrm{m})$. The droplet volume $\mathrm{D}_{50}$ of the tested nozzles (factor B) also showed an extremely significant difference

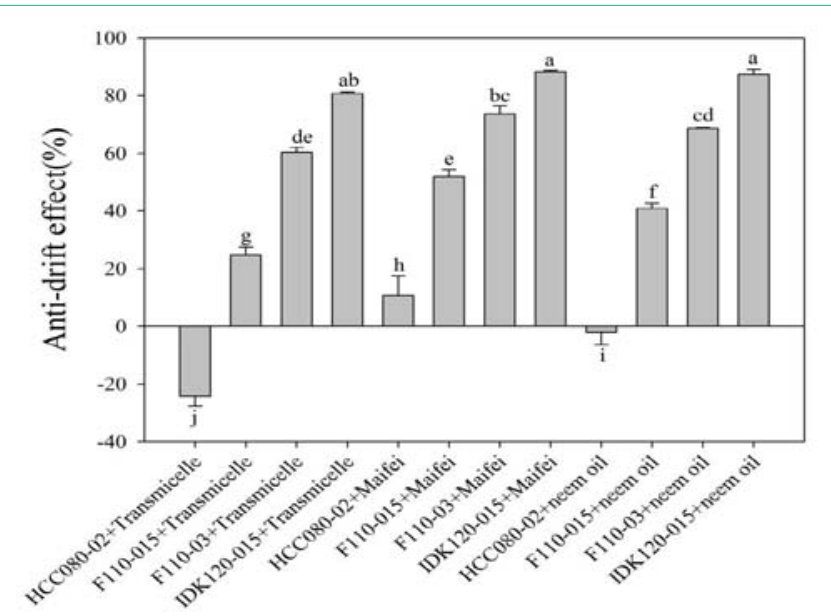

Figure 3: Comparison of anti-floating effect of different treatment. Different letters $(a, b)$ above bars indicate significant differences $(P<0.05)$, the same letter is not significantly different $(P>0.05)$ according to Duncan's multiple range test. The F11, 24 values of different treatments on anti-floating effect of different adjutants and nozzles was 150.917 , and the $P$ values of different treatments on anti-floating effect of different adjutants and nozzles was = $0.000<0.01$.

$(\mathrm{F}=55.353, \mathrm{df}=3, \mathrm{P}=0.000<0.01)$, and the D50 value of nozzle IDK120-015 $(313.1 \mu \mathrm{m})$ was the lowest, followed by those of F110$03(405.5 \mu \mathrm{m})$ and F110-015 $(446.7 \mu \mathrm{m})$, whereas that of HCC80-02 $(847.5 \mu \mathrm{m})$ was the highest. The $\mathrm{D}_{50}$ values of different drift distances (factor C) were extremely different $(\mathrm{F}=93.305, \mathrm{df}=2, \mathrm{P}=0.000<$ $0.01)$, among which those of $3 \mathrm{~m}(238.2 \mu \mathrm{m})$ and $2 \mathrm{~m}(438.7 \mu \mathrm{m})$ were significantly lower than that of $1 \mathrm{~m}(808.0 \mu \mathrm{m})$, and the difference 
Table 5: Multiple comparison of drift deposition percentage per Mylar (pv).

\begin{tabular}{|l|c|c|c|c|}
\hline \multicolumn{1}{|c|}{ Adjutants } & pv \pm SD (\%) & Nozzles & pv \pm SD (\%) & Drift distance \\
\hline Transmicelle & $0.080 \pm 0.067^{\mathrm{aA}}$ & F110-015 & $0.075 \pm 0.033^{\mathrm{bB}}$ & $1 \mathrm{~m}$ \\
\hline Maifei & $0.056 \pm 0.051^{\mathrm{cC}}$ & IDK120-015 & $0.017 \pm 0.012^{\mathrm{dD}}$ & $2 \mathrm{~m}$ \\
\hline Neem oil & $0.064 \pm 0.056^{\mathrm{bB}}$ & F110-03 & $0.043 \pm 0.023^{\mathrm{cC}}$ & $0.066 \pm 0.047^{\mathrm{bB}}$ \\
\hline & & HCC80-02 & $0.134 \pm 0.066^{\mathrm{aA}}$ & $3 \mathrm{~m}$ \\
\hline
\end{tabular}

Note: SD is standard deviation. Means within a row followed by different lowercase and uppercase letters are significantly different using the paired bootstrap tes procedure $(\mathrm{P}<0.05, \mathrm{P}<0.01$, respectively)

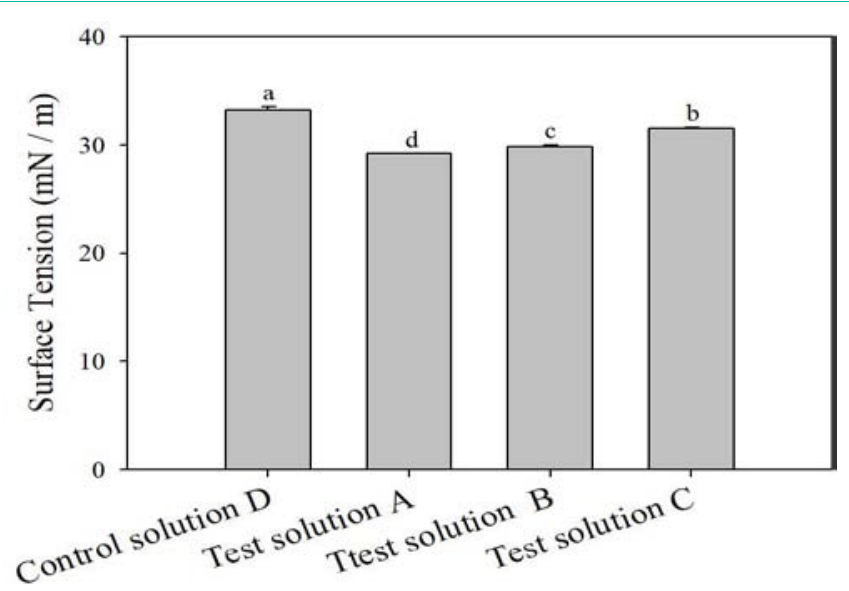

Figure 4: Effect of different adjuvants on surface tension of liquids. Different letters $(a, b)$ above bars indicate significant differences $(P<0.05)$, and the same letter is not significantly different $(P>0.05)$ according to Duncan's multiple range test. The test solution $A, B, C$ and control solution D respectively mean mother liquor separately appended $5 \mathrm{mg} / \mathrm{L}$ Maifei, Neem oil, Transmicelle and equal volumes of water. The F3, 8 values of different treatments on surface tension of different adjutants was 97.638 and the $\mathrm{P}$ values of different treatments on surface tension of different adjutants was $=0.000<0.01$.

between $3 \mathrm{~m}$ and $2 \mathrm{~m}$ was also significant. Among multiple factors, the interaction between factors $\mathrm{A}$ and $\mathrm{B}$ was extremely significant $(\mathrm{A} \times \mathrm{B}$ $\times \mathrm{F}=5.592, \mathrm{df}=5, \mathrm{P}=0.001<0.01)$; the interaction between factors $\mathrm{A}$ and $\mathrm{C}$ was significant $(\mathrm{A} \times \mathrm{C} \times \mathrm{F}=3.375, \mathrm{df}=4, \mathrm{P}=0.018<0.05)$; the interaction between factors $B$ and $C(B \times C \times F=15.491, d f=6, P$ $=0.000<0.01)$ and factors $\mathrm{A}, \mathrm{B}$, and $\mathrm{C}(\mathrm{A} \times \mathrm{B} \times \mathrm{C} \times \mathrm{F}=3.046, \mathrm{df}=10$, $\mathrm{P}=0.006<0.01)$ also reached extremely significant levels.

The $S$ of droplets deposited by different adjuvants and nozzles drifted at different distances was tested by scanning the photo paper, and the results are shown in Tables 5 . The results showed that there was no significant difference in the $\mathrm{S}$ among the tested adjuvants (factor A) $(\mathrm{F}=1.886, \mathrm{df}=2, \mathrm{P}=0.165>0.05)$. In contrast, an extremely significant difference in $\mathrm{S}$ was observed among the different nozzles (factor $\mathrm{B})(\mathrm{F}=23.190, \mathrm{df}=3, \mathrm{P}=0.000<0.01)$, of which the $S$ value of nozzle IDK120-015 (0.728) was significantly lower than those of HCC80-02 (1.213), F110-015 (1.099), and F110-03 (1.063). Meanwhile, extremely significant differences in $\mathrm{S}$ were observed for the drift distances (factor $\mathrm{C})(\mathrm{F}=30.408, \mathrm{df}=2, \mathrm{P}=0.000<0.01)$; the $S$ at $3 \mathrm{~m}(0.797)$ was significantly lower than those at $1 \mathrm{~m}(1.217)$ and $2 \mathrm{~m}$ (1.05). Among the multiple factors, the interactions between factors $\mathrm{A}$ and $\mathrm{B}(\mathrm{A} \times \mathrm{B} \times \mathrm{F}=2.502, \mathrm{df}=5, \mathrm{P}=0.046<0.05)$ and $\mathrm{A}$ and $\mathrm{C}(\mathrm{A} \times \mathrm{C} \times \mathrm{F}=3.298, \mathrm{df}=4, \mathrm{P}=0.02<0.05)$ were significant, whereas the interactions between factors $\mathrm{B}$ and $\mathrm{C}(\mathrm{B} \times \mathrm{C} \times \mathrm{F}=2.171, \mathrm{df}=6, \mathrm{P}$

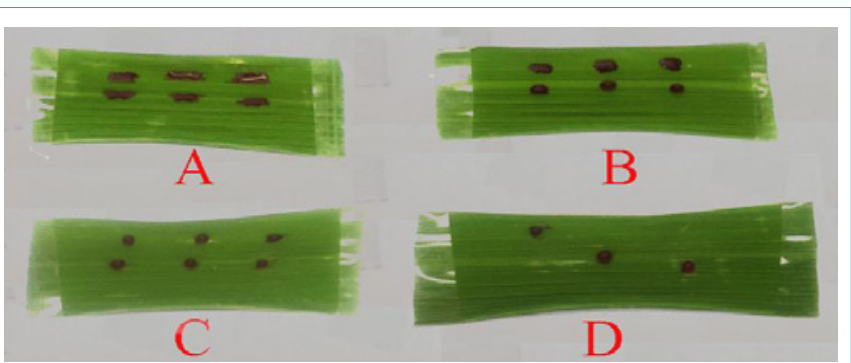

Figure 5: Effect of different adjuvants on the spreading ability on rice leaves. A, B, C and D respectively mean mother liquor separately appended $5 \mathrm{mg} / \mathrm{L}$ Maifei, Neem oil, Transmicelle and equal volumes of water.

$=0.066>0.05)$ and factors $\mathrm{A}, \mathrm{B}$ and $\mathrm{C}(\mathrm{A} \times \mathrm{B} \times \mathrm{C} \times \mathrm{F}=0.765, \mathrm{df}=10$, $\mathrm{P}=0.661>0.05)$ were not significant.

The drift deposition amounts for different adjuvants and nozzles at different distances were also estimated by scanning the photo paper. The results showed that the estimated drift deposition amounts were significantly different among the tested adjuvants (factor A) (F $=4.981, \mathrm{df}=2, \mathrm{P}=0.012<0.05)$. Additionally, the estimated drift deposition amounts for the different nozzles (factor B) were extremely significantly different $(\mathrm{F}=67.899, \mathrm{df}=3, \mathrm{P}=0.000<0.01)$; the estimated drift deposition amount of nozzle IDK120-015 $(0.595 \mu \mathrm{L} /$ $\left.\mathrm{cm}^{2}\right)$ was the least, followed by those of F110-03 $\left(1.81 \mu \mathrm{L} / \mathrm{cm}^{2}\right)$ and F110-015 $\left(2.063 \mu \mathrm{L} / \mathrm{cm}^{2}\right)$, and the highest estimated drift deposition amount was for HCC $80-02\left(4.271 \mu \mathrm{L} / \mathrm{cm}^{2}\right)$. The influence of the estimated drift deposition amount on the drift distance (treatment C) was extremely significant $(\mathrm{F}=89.704, \mathrm{df}=2, \mathrm{P}=0.000<0.01)$; the estimated drift deposition amount of the $3 \mathrm{~m}\left(0.643 \mu \mathrm{L} / \mathrm{cm}^{2}\right)$ treatment was extremely significantly lower than those of the $2 \mathrm{~m}\left(1.905 \mu \mathrm{L} / \mathrm{cm}^{2}\right)$ and $1 \mathrm{~m}\left(3.868 \mu \mathrm{L} / \mathrm{cm}^{2}\right)$ treatments. The interactions between factors $\mathrm{A}$ and $\mathrm{C}(\mathrm{A} \times \mathrm{C} \times, \mathrm{F}=3.570, \mathrm{df}=4, \mathrm{P}=0.014<0.05)$ and factors $\mathrm{A}, \mathrm{B}$ and $\mathrm{C}(\mathrm{A} \times \mathrm{B} \times \mathrm{C} \times \mathrm{F}=2.660, \mathrm{df}=10, \mathrm{P}=0.014<0.05)$ also reached $\mathrm{a}$ significant level. Additionally, the interactions between factors $A$ and $\mathrm{B}(\mathrm{A} \times \mathrm{B} \times \mathrm{F}=5.171, \mathrm{df}=5, \mathrm{P}=0.001<0.01)$ and factors $\mathrm{B}$ and $\mathrm{C}(\mathrm{B}$ $\times C \times F=14.406, d f=6, P=0.000<0.01)$ were extremely significant.

\section{Effect of different adjuvants and nozzles on the percentage of drift deposition per mylar}

The drift amounts of different nozzles at different distances were measured by eluting the microcards, and the drift deposition percentages per Mylar pv of each treatment were calculated according to the formula above. The results indicated that pv was extremely significant among the tested adjuvants (factor $\mathrm{A})(\mathrm{F}=43.212$, df $=2, \mathrm{P}=0.000<0.01)$, the pv result of the Transmicelle treatment $(0.080 \%)$ was significantly higher than those of the Maifei and neem oil treatment $(0.056 \%$ and $0.064 \%$, respectively); the pv of different 
nozzles (factor B) was extremely significant $(\mathrm{F}=569.530 \mathrm{df}=3$, $\mathrm{P}=0.000<0.001)$, while that of nozzle IDK120-015 $(0.017 \%)$ was the least significant among the treatments, followed by F110-03 (0.043\%), F110-015 (0.075\%), and the pv of HCC $80-02$ (0.134\%) was the highest (most significant) among the other treatments; the pv of the drift distance (factor $\mathrm{C}$ ) was extremely significant $(\mathrm{F}=409.076, \mathrm{df}$ $=2, \mathrm{P}=0.000<0.01)$, the highest of which was for the $1 \mathrm{~m}(0.105 \%)$ treatment, followed by the $2 \mathrm{~m}(0.066 \%)$ and $3 \mathrm{~m}(0.030 \%)$ treatments Among the multiple factors, the interactions between factors $\mathrm{A}$ and $\mathrm{B}$ $(\mathrm{A} \times \mathrm{B} \times \mathrm{F}=4.652, \mathrm{df}=6, \mathrm{P}=0.000<0.01)$, factors $\mathrm{A}$ and $\mathrm{C}(\mathrm{A} \times \mathrm{C}$ $\times, \mathrm{F}=2.112, \mathrm{df}=4, \mathrm{P}=0.0088<0.01)$ and factors $\mathrm{B}$ and $\mathrm{C}(\mathrm{B} \times \mathrm{C} \times \mathrm{F}$ $=50.191, \mathrm{df}=6, \mathrm{P}=0.000<0.01)$ all indicated extremely significant interactions; nevertheless, the interactions between factors $\mathrm{A}, \mathrm{B}$ and $\mathrm{C}$ were not significant $(\mathrm{A} \times \mathrm{B} \times \mathrm{C} \times \mathrm{F}=0.657, \mathrm{df}=12, \mathrm{P}=0.786>0.05)$.

\section{Anti-drift effect of different adjuvants and nozzles}

The anti-drift effect of each treatment is shown in Figure 2. For the same adjuvants, HCC080-02 (-24.168\% 10.798\%) increased the drift, while F110-03 (60.355\% 73.624\%) and IDK120-015 (80.711\% 88.302\%) reduced the drift compared with the results of F110-15 (24.765 51.855\%). For the same nozzle, the anti-drift effects of Maifei (10.798\% 88.302\%) and neem oil (-2.177\% 87.291\%) were significantly higher than those of Transmicelle (-24.168\% 80.711\%); the IDK120-015 nozzle with Maifei and neem oil had significantly higher anti-drift effects than those with other adjuvants, reaching $87.291 \% \sim 88.302 \%$ (Figure 3).

\section{Effect of different adjuvants on the surface tension of liquids}

The surface tension of the blank control solution $\mathrm{D}(33.2 \mathrm{mN} / \mathrm{m})$ was significantly higher than those of the other tested solutions $(\mathrm{P}<$ 0.05), for example, those of $\mathrm{C}(31.5 \mathrm{mN} / \mathrm{m})$ and $\mathrm{B}(29.9 \mathrm{mN} / \mathrm{m})$. The surface tension of solution A $(29.2 \mathrm{mN} / \mathrm{m})$ was the lowest among the treatments $(\mathrm{P}<0.05)$ (Figure 4). Additionally, the use of adjuvants could significantly increase the spreading ability, opposite to the surface tension, and the greatest influence was observed for the adjuvant Maifei.

\section{Discussion}

\section{Effect of different adjuvants on spray atomization performance}

The complex process of spraying the chemical liquid on the organism surface and generating biological effects included atomization, spray delivery, impact, wetting, retention, drug diffusion and biological effects; the atomization performance, which directly affected the loss of pesticides and deposition behavior [9,25-27]. The addition of adjuvants to crop protection agents has become increasingly important to enhance the efficacy of crop protection products, due to factors such as droplet drift reduction, evaporation, and improved droplet spreading on leaf surfaces of plants [28,29]. Our results suggested that neem oil could significantly decrease the $S$ value compared with that of the blank control, whereas the $\mathrm{S}$ and $\mathrm{D}_{50}$ values significantly increased due to the addition of other adjuvants, even though the $\Phi \mathrm{Vol}_{<150 \mu \mathrm{m}}$ values were significantly reduced; in contrast, the $\mathrm{D}_{50}$ values of neem oil and Maifei were the largest among all the results. Under the high deformation processes in a spray nozzle, the addition of the adjuvant SDS could shift the droplet size distribution to larger droplet sizes [30]. However, Santos et al. [31] found that the addition of mineral oil resulted in a higher $\mathrm{D}_{50}$ and uniformity coefficient of droplets. The spray adjuvants can change the properties of the solution, which was beneficial to the wetting and spreading of the droplets on the target and avoided the loss of control agents [32].

\section{Effect of spray performance parameters on drifting}

Since the drift was closely related to spray droplet size [33], the smaller a spray droplet, the longer it remained airborne and the higher the possibility of drifting by crosswind; moreover, spray droplets of a few microns in size could evaporate before deposition [34]. Our results showed that the estimated drift deposition amount and percentage of drift amount at $3 \mathrm{~m}$ was significantly lower than those at $1 \mathrm{~m}$ and $2 \mathrm{~m}$, which had a smaller $\mathrm{D}_{50}$ values. Kirk [35] reported that $\mathrm{D}_{50}$ had a profound influence on droplet drift, and França et al. [36] also found that there was an inverse correlation between drift potential and $\mathrm{D}_{50}$, which indicates that $\mathrm{D}_{50}$ could be used to predict the behavior of drift risk, and the addition of a mineral oil adjuvant could result in an increase in the velocity of droplets and reduced drift. Our results showed that the $\mathrm{D}_{50}$ of the adjuvant Transmicelle with a higher drift deposition percentage was lower than those of Maifei and neem oil. Collin et al. [37] found that 63\% drift reduction was achieved by incorporating certain spray adjuvants, and the wind tunnel data for droplet spectra also showed strong agreement with field deposition trends. Stainier et al. [25] evaluated the effects of 4 adjuvants on two formulations of phenmedipham applied with three types of hydraulic nozzles using a wind tunnel, and the results were also consistent with ours. However, Ferguson et al. [38] found that the addition of adjuvant DRT oil was an effective way to reduce the spray solution drift potential across all nozzle types, but the greatest reduction in drift potential could be achieved by changing the nozzle type. Therefore, our results showed that the estimated drift deposition amount and the drift percentage of nozzle IDK120015 were significantly lower than those of HCC80-02, F110-015 and F110-03. Franca et al. [36] compared the droplet diameter, velocity, and potential drift index of air-induction nozzles with those of conventional nozzles using an open-wind tunnel and found that air-induction nozzles produced larger droplets but did not affect the spray speed, thereby reducing the potential drift index. Air-induction nozzles can promote the formation of larger and less homogeneous droplets, without considerably affecting the velocity of the droplets.

\section{Effect of air-induction nozzle and adjuvants on drift and surface tension}

The most common recommendation for reducing drift was to use coarser droplets (a smaller fraction of fine droplets), mainly using air-induction nozzles or anti-drift adjuvants to eliminate some small droplets produced by spray [31,37], because small droplets would deviate from the target due to the wind. Our results showed that the anti-drift effect from plant protection drones with the use of the airinduction nozzle IDK120-015 and adjuvant Maifei was significantly higher than those of other nozzles or adjuvants, similar to the results of Creech et al. [29] Fornasiero et al. [39] also found that low-drift nozzles or normal nozzles with anti-drift adjuvant could decrease potential drift and effectively control pests.

Carvalho et al. [40] found that the emulsifiable concentrate formulation, which resulted in the lowest surface tensions, was 
more effective at decreasing the driftable fines than the water dispersible granule and suspension concentrate formulations. Wang et al. [30] found that the addition of associative SDS to a base dilute poly (ethylene oxide) solution decreased the dynamic surface tension, slightly increased the initially zero shear viscosity, substantially enhanced the extensional properties of the solutions, and substantially reduced the spray drift. Our results also showed that the addition of adjuvant Maifei significantly reduced the surface tension of the liquids. The smaller the surface tension was, the better the droplet spread [41]. Feng et al. [42] found that large droplets have slightly reduced retention in corn but have significantly increased absorption, promoting the translocation of glyphosate to the growing sink tissues. The coarser droplets produced by the low-drift nozzles and anti-drift adjuvant did not reduce the efficacy of the insecticides, unlike the high-drift nozzles under the same operating parameters. In general, both these approaches can provide sufficient and uniform fruit coverage of insecticides [39].

\section{Conclusion}

We evaluated the spray atomization performance of different adjuvants by the droplet size measurement system, and found that the addition of adjuvants would modify the distribution span $\mathrm{S}$, $\Phi \mathrm{Vol}_{<150 \mu \mathrm{m}}$ and $\mathrm{D}_{50}, \Phi \mathrm{Vol}_{<150 \mu \mathrm{m}}$ and $\mathrm{D}_{50}$ of the Maifei treatment decreased and increased the most of all the treatments. In the wind tunnel, we found that there were negative correlations between the drift distance, $\mathrm{D}_{50}$ and percentage of drift amount; the adjuvants Maifei and the nozzle IDK120-015 significantly decreased the drift deposition amount. And the anti-drift effect of nozzle IDK120-015 plus Maifei was significantly stronger than that of other nozzles or adjuvants. The surface tension of different adjuvants measured by an automatic surface tension meter showed that the addition of adjuvants could significantly decrease the surface tension, especially for Maifei. These results suggest that the addition of Maifei could be an effective way to reduce the spray solution drift with all nozzle types and decrease the surface tension of liquids.

\section{Acknowledgements}

This work was supported by the National Key R\&D Program of China (2018YFD0200300).

\section{Authors Contribution}

XW designed the research. CG, YM and XW performed the assays. CG, XZ, RY, YR, LS and XZ analyzed the data. XW and CG wrote the manuscript.

\section{References}

1. Yuan HZ, Yang DB, Yan XJ. Pesticide efficiency and the way to optimize the spray application. Plant Prot. 2011; 5: 14-20.

2. Xue $X Y$, Lan YB. Agricultural aviation applications in USA. Trans. Chin. Soc. Agric. Mach. 2013; 44: 194-201.

3. Qin WC, Qiu BJ, Xue XY, Chen, C, Xu ZF, Zhou QQ. Droplet deposition and control effect of insecticides sprayed with an unmanned aerial vehicle against plant hoppers. Crop Prot. 2016; 85: 79-88.

4. Antuniassi UR, Carbonari CA, Velini ED, Oliveira RB, Oliveira MA, Mota AA Spray drift from aerial application on sugarcane in Brazil. Phytopathology. 2011; 101: 8.

5. Hoffmann WC, Fritz BK, Thornburg JW, Bagley WE, Ellenberger J. Spray drift reduction evaluations of spray nozzles using a standardized testing protocol.

\section{J. ASTM Int. 2010; 7: 10}

6. Hoffmann WC, Hewitt AJ, Ross JB, Bagley WE, Fritz BK. Spray adjuvan effects on droplet size spectra measured by three laser-based systems in a high-speed wind tunnel. J. ASTM Int. 2008; 5: 101233-101244.

7. He Y, Xiao S, Fang H, Dong T, Nie PC, Wu JJ, et al. Development situation and spraying decision of spray nozzle for plant protection UAV. T. ASABE. 2018; 34: 113-124.

8. Flack SL, Ledson TM, Ramanarayanan TS. Particle size characterization of agricultural sprays collected on personal air monitoring samplers. J. Agric. Saf. Health. 2019; 25: 91-103.

9. Bertola V. Effect of polymer adjutants on the apparent dynamic contact angle of impacting drops. Colloids Surf. A Physicochem Eng. Asp. 2010; 363: 135140.

10. Hilz E, Vermeer AW. Spray drift review: The extent to which a formulation can contribute to spray drift reduction. Crop Prot. 2013; 44: 75-83.

11. Heidary AM, Douzals JP, Sinfort C, Vallet A. Influence of spray characteristics on potential spray drift of field crop sprayers: A literature review. Crop Prot. 2014; 63: 120-130.

12. Butler-Ellis MC, Swan T, Miller PCH, Waddelow S, Bradley A, Tuck CR. Design factors affecting spray characteristics and drift performance of air induction nozzles. Biosyst. Eng. 2002; 82: 289-296.

13. Ellis MB, Tuck CR, Miller PCH. The effect of some adjuvants on sprays produced by agricultural flat fan nozzles. Crop Prot. 1997; 16: 41-50.

14. Nuyttens D, Baetens K, De Schampheleire M, Sonck B. Effect of nozzle type, size and pressure on spray droplet characteristics. Biosyst. Eng. 2007; 7 333-345.

15. Wahono S, Honnery D, Soria J, Ghojel J. High-speed visualization of primary break-up of an annular liquid sheet. Exp. Fluids. 2008; 44: 451-459.

16. Dandapat BS, Maity S, Kitamura A. Liquid film flow due to an unsteady stretching sheet. Int. J. Non. Linear Mech. 2008; 43: 880-886.

17. Palacios E, Nogueira J, Rodríguez PA, Lecuona A. Experimental characterization of the spreading and break-up of liquid flat-fan sheets discharging in a low-density atmosphere and application to BrLi solutions. Exp. Fluids. 2009; 46: 331-342.

18. Negeed ESR, Hidaka S, Kohno M, Takata Y. Experimental and analytical investigation of liquid sheet breakup characteristics. Int. J. Heat Fluid Flow. 2001; 32: 95-106

19. Miller DR, Thomas ES. Response of spray drift from aerial applications at a forest edge to atmospheric stability. Agric. For Meteorol. 2000; 1: 49-58.

20. Wang X, He X, Wang C, Wang Z, Li L, Wang S, et al. Spray drift characteristics of fuel powered single-rotor UAV for plant protection. Trans. CSAE. 2017; 33 117-123.

21. Smith DB, Bode LE, Gerard PD. Predicting ground boom spray drift. T. ASAE. 2000; 43: 547-553.

22. Zhong H, Chen G, Li Y. Droplets size measurement of upward sprinkling nozzle based on photography. Trans. CSAE. 2015; 31: 46-51.

23. Zhu H, Salyani M, Fox RD. A portable scanning system for evaluation of spray deposit distribution. Comput. Electron. Agric. 2011; 76: 38-43.

24. Li C, Chen L, Ren Z. Application of ring method to measure surface tensions of liquids in high magnetic field. Rev. Sci. Instrum. 2012; 83: 043906

25. Stainier C, Destain MF, Schiffers B, Lebeau F. Droplet size spectra and drift effect of two phenmedipham formulations and four adjuvants mixtures. Crop Prot. 2006; 25: 1238-1243.

26. Werner SR, Jones JR, Paterson AH, Archer RH, Pearce DL. Droplet impact and spreading: Droplet formulation effects. Chem. Eng. Sci. 2007; 62: 23362345.

27. Wang MJ, Lin FH, Ong JY, Lin SY. Dynamic behaviors of droplet impact and spreading-water on glass and paraffin. Colloid Surface A. 2009; 339: 224-231. 
28. Griesang F, Decaro RA, dos Santos CAM, Santos ES, de Lima Roque NH, da Costa Ferreira M. How much do adjuvant and nozzles models reduce the spraying drift? Drift in agricultural spraying. Am. J. Plant Sci. 2017; 8: 2785-2794.

29. Creech CF, Henry RS, Hewitt AJ, Kruger GR. Herbicide spray penetration into corn and soybean canopies using air-induction nozzles and a drift contro adjuvant. Weed Technol. 2018; 32: 72-79.

30. Wang R, Dorr G, Hewitt A, Cooper-White J. Impacts of polymer/surfactant interactions on spray drift. Colloid Surface A. 2016; 500: 88-97.

31. Santos CAMD, Santos RTDS, Della'Vechia J, Griesang F, Polanczyk RA Ferreira MDC. Effect of addition of adjuvants on physical and chemical characteristics of Bt bioinsecticide mixture. Sci. Rep. 2019; 9: 1-8.

32. Schleier JJ, Preftakes C, Peterson RK. The effect of fluorescent tracers on droplet spectrum, viscosity, and density of pesticide formulations. J. Environ. Sci. Health B. 2010; 45: 621-625.

33. Miller PC, Tuck CR. Factors influencing the performance of spray delivery systems: A review of recent developments. J. ASTM Int. 2005; 2: 1-13.

34. Ferguson JC, O'Donnell CC, Chauhan BS, Adkins SW, Kruger GR, Wang $\mathrm{RB}$, et al. Determining the uniformity and consistency of droplet size across spray drift reducing nozzles in a wind tunnel. Crop Prot. 2015; 76: 1-6.

35. Kirk IW. Measurement and prediction of atomization parameters from fixedwing aircraft spray nozzles. T. ASABE. 2007; 50: 693-703.
36. França JA, da Cunha JP, Antuniassi UR. Spectrum, velocity and drift of droplets sprayed by nozzles with and without air induction and mineral oil. Eng. Agr. 2017; 37: 502-509.

37. Collin JP, Jerome JS, Greg RK, David KW, Robert KDP. Effect of insecticide formulation and adjuvant combination on agricultural spray drift. Peer J. 2019; 7: e7136.

38. Ferguson JC, Chechetto RG, O'Donnell CC, Dorr GJ, Moore JH, Bake GJ, et al. Determining the drift potential of venturi nozzles compared with standard nozzles across three insecticide spray solutions in a wind tunnel. Pest Manag. Sci. 2016; 72: 1460-1466.

39. Fornasiero D, Mori N, Tirello P, Pozzebon A, Duso C, Tescari E, et al. Effect of spray drift reduction techniques on pests and predatory mites in orchards and vineyards. Crop Prot. 2017; 98: 283-292.

40. Carvalho FK, Antuniassi UR, Chechetto RG, Mota AAB, de Jesus MG, de Carvalho LR. Viscosity, surface tension and droplet size of sprays of different formulations of insecticides and fungicides. Crop Prot. 2017; 101: 19-23.

41. Buick RD, Buchan GD, Field RJ. The role of surface tension of spreading droplets in absorption of an herbicide formulation via leaf stomata. J. Pestic. Sci. 1993; 38: 227-235.

42. Feng PC, Chiu T, Sammons RD, Ryerse JS. Droplet size affects glyphosate retention, absorption, and translocation in corn. Weed Sci. 2003; 51: 443-448. 